\title{
Poor outcome of comprehensive therapy in a case of laryngeal synovial sarcoma
}

\author{
Yang-Yang Bao1, Quin-Ying Wang¹, Shui-Hong Zhou¹, Kui Zhao², Ling-Xiang Ruan³, \\ Hong-Tian Yao

\begin{abstract}
${ }^{1}$ Department of Otolaryngology, ${ }^{2}$ Department of PET/CT centre, ${ }^{3}$ Department of Radiology, ${ }^{4}$ Department of Pathology, The First Affiliated Hospital, College of Medicine, Zejiang University, Hangzhou, Zhejiang, China
\end{abstract}

Radiol Oncol 2013; 47(2): 111-118.

Received 3 August 2012

Accepted 10 February 2013

Correspondence to: Dr Shui-Hong Zhou, Ph.D, The First Affiliated Hospital, College of Medicine, Zhejiang University, Quingchun road 79, Hangzhou; Zhejiang, China, 310003. Phone: 86-13868060120; Fax: 86-571-87236895; E-mail: zhouyunzhoush@163.com

Disclosure: No potential conflicts of interest were disclosed.

Background. Synovial sarcoma is common in the extremities. Our search revealed only 17 cases of synovial sarcoma of the larynx in the English-language literature.

Case report. We report an additional case of a 37-year-old man with primary laryngeal synovial sarcoma who underwent positron emission tomography/computed tomography (PET/CT) following the treatment. Although the patient received comprehensive therapy including surgery, radiotherapy, repeated chemotherapies, and targeted therapies, he had an unfavourable outcome and died of distant metastases.

Conclusions. In synovial sarcoma of the larynx, PET/CT can detect recurrence and metastasis. PET/CT can also predict the treatment effect in patients with synovial sarcoma.

Key words: synovial sarcoma; larynx; PET/CT; follow up

\section{Introduction}

Synovial sarcoma is common in the extremities. ${ }^{1}$ Only $3-9 \%$ of all cases of synovial sarcoma occur in the head and neck region, and the least frequent site of occurrence is the larynx.,3 Our search revealed only 17 cases of synovial sarcoma of the larynx in the English-language literature. ${ }^{2-18}$

Since few cases of laryngeal synovial sarcoma have been reported, its histogenesis, natural history, optimal treatment strategy, and long-term prognosis are unknown. Most primary synovial sarcomas of the head and neck metastasise to the lungs; among these, only a few cases were reported to have cervical metastases. ${ }^{19}$ The local recurrence rate of synovial sarcoma is $8-60 \%$. Tumours usually recur within 2 years of the initial therapy. ${ }^{20}$ The diagnostic workup for recurrence or metastasis of synovial sarcoma involves conventional imaging, including computed tomography (CT) and magnetic resonance imaging (MRI). ${ }^{21}$ During the past decade, ${ }^{18} \mathrm{~F}$-fluorodeoxyglucose $\left({ }^{18} \mathrm{FDG}\right)$ positron emission tomography (PET)/CT has become an adjunct tool to conventional imaging in the staging and follow-up of sarcoma. ${ }^{22} \mathrm{~A}$ few reports have described the use of PET/CT for synovial sarco$\mathrm{ma}^{1,20,23}$, and no report has presented the PET/CT features of laryngeal synovial sarcoma.

In the majority of cases, the surgical excision with a wide margin is the first treatment choice. The effect of chemotherapy or radiotherapy is controversial. ${ }^{24-26}$ We report a case of a patient with primary laryngeal synovial sarcoma who underwent PET/CT following treatment. Although the patient received comprehensive therapy including surgery, radiotherapy, repeated chemotherapies, and targeted therapies, he had an unfavourable outcome and died of whole-body metastasis in November 2011. 


\section{Case report}

On 4 June 2008, a 37-year-old man was referred to our department due to a 1-month history of sore throat and blood in the phlegm. He also complained of dysphagia. He denied hoarseness and respiratory dyspnoea. His medical history was unremarkable. Laryngoscopy showed a $2 \times 2.5 \mathrm{~cm}$ wine-coloured tumour in the right aryepiglottic fold that involved the inner wall of the right piriform sinus. The surface was covered with blood clots. The motion of the bilateral vocal cords and the remainder of the larynx appeared normal. Cervical lymphadenopathy was absent. CT revealed a $3.5 \times 2.2 \mathrm{~cm}$ irregular soft-tissue mass in the right aryepiglottic fold extending to the right piriform sinus, with low to moderate heterogeneous enhancement after the injection of contrast medium. No enlarged node
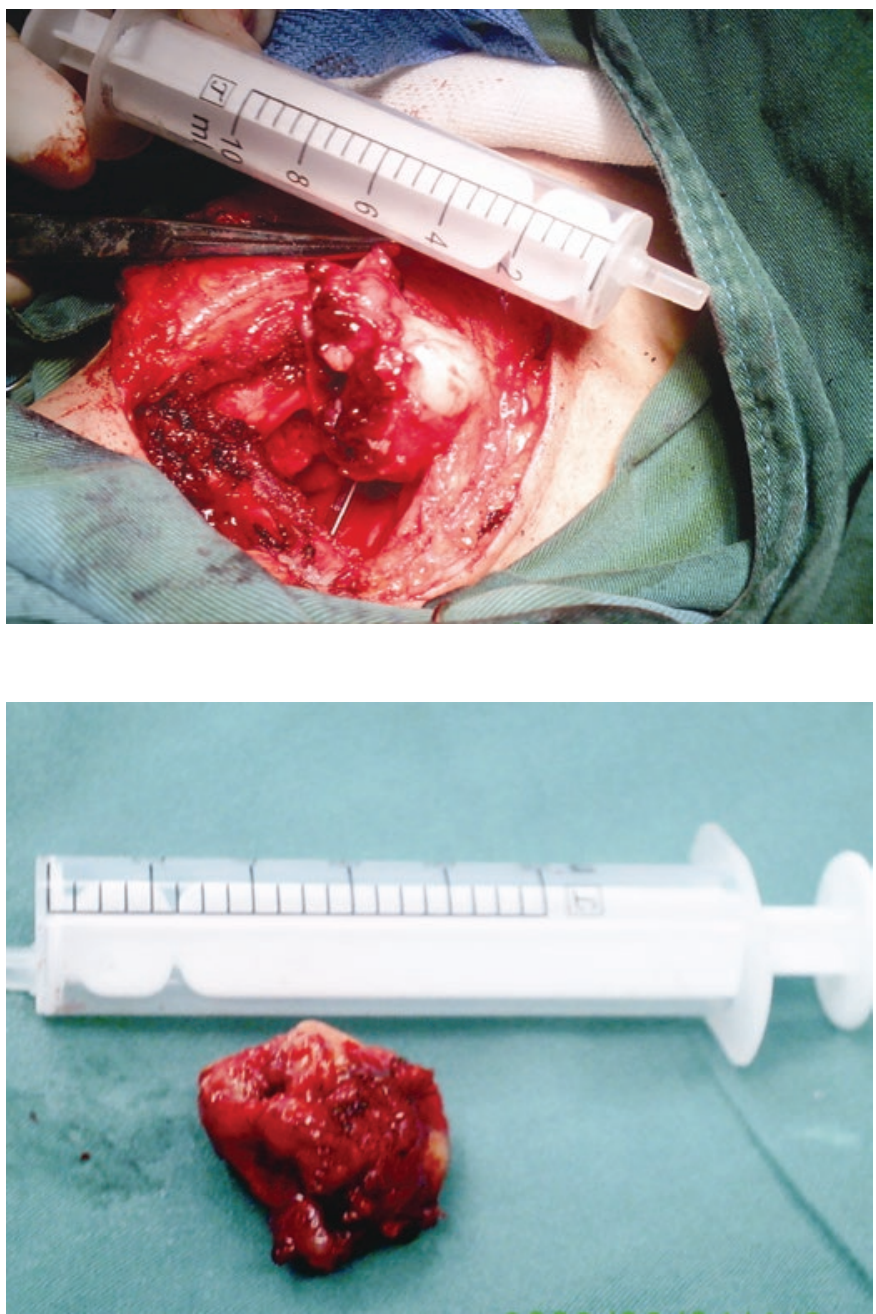

FIGURE 1. (a) The mass was tan-red and irregular and had an ulcer covered by blood clots and a fleshy cut surface. (b) Surgical sample. was present. Under general anaesthesia (a tracheotomy was performed), biopsy was performed by suspension laryngoscopy. The frozen section results suggested that the tumour was a spindle cell tumour. The tumour was removed completely via lateral cervical incision and partial laryngectomy. The laryngeal function was preserved. During the operation, we found that the tumour was located in the right supraglottic area, with a pedicle in the right aryepiglottic fold extending to the right piriform sinus. Mass was tan-red and irregular and had an ulcer covered by blood clots and a fleshy cut surface (Figure 1).

The postoperative pathological results showed that the tumour consisted of small, uniform spindle cells invading the surrounding muscles. The immunohistochemical examination for vimentin and CD99 was positive. Epithelial membrane antigen was focal positive. These results led to a diagnosis of monophasic synovial sarcoma. The resection margins were tumour free (Figure 2).

Postoperative radiotherapy was given; the total dose was 66 Gy. On 26 October 2009, MRI of the head and neck revealed a $1 \times 2 \mathrm{~cm}$ mass in the region of the right hypopharynx and laryngeal inlet. On 4 November 2009, ${ }^{18}$ FDG-PET/CT demonstrated high FDG uptake coincident with MRI findings (standardised uptake value $[S U V]_{\max }=4.1$ ) and no distant metastases (Figure 3). A partial laryngopharyngectomy was performed. After surgery, the patient was followed regularly at 2-month intervals with CT or MRI examination of the head and neck.

In August 2010, CT of the head and neck revealed a $3.6 \times 2.6 \mathrm{~cm}$ mass in the right submaxillary region. Further CT of the lungs revealed bilateral lung metastases. PET/CT revealed high FDG uptake in the right submaxillary lymph node $\left(\mathrm{SUV}_{\max }=3.2\right)$, right oropharynx $\left(\mathrm{SUV}_{\max }=5.4\right)$, and multiple nodules in the bilateral lungs $\left(\mathrm{SUV}_{\max }=4.6\right.$; Figure 4$)$. These results suggested local recurrence and cervical lymph node and lung metastases. The patient received chemotherapy and concurrent targeted treatment comprising adriamycin $\left(40 \mathrm{mg} / \mathrm{m}^{2}\right.$, days 1-2), ifosfamide (2 $\mathrm{g} / \mathrm{m}^{2}$, days $\left.1-4\right)$, dacarbazine (300 mg/m², days 1-4), and anti-epidermal growth factor receptor monoclonal antibody (nimotuzum$\mathrm{ab}, 200 \mathrm{mg} / \mathrm{m}^{2}$, days 1-4). The patient underwent three cycles of chemotherapy at 3-week intervals. On 18 November 2010, the first-line therapy package was completed. The cervical mass was treated with intratumoural injection of recombinant adenovirus p53 agent injection once a week for 4 weeks and another four cycles of nimotuzumab 
TABLE 1 English-Literature review of synovial sarcomas of larynx

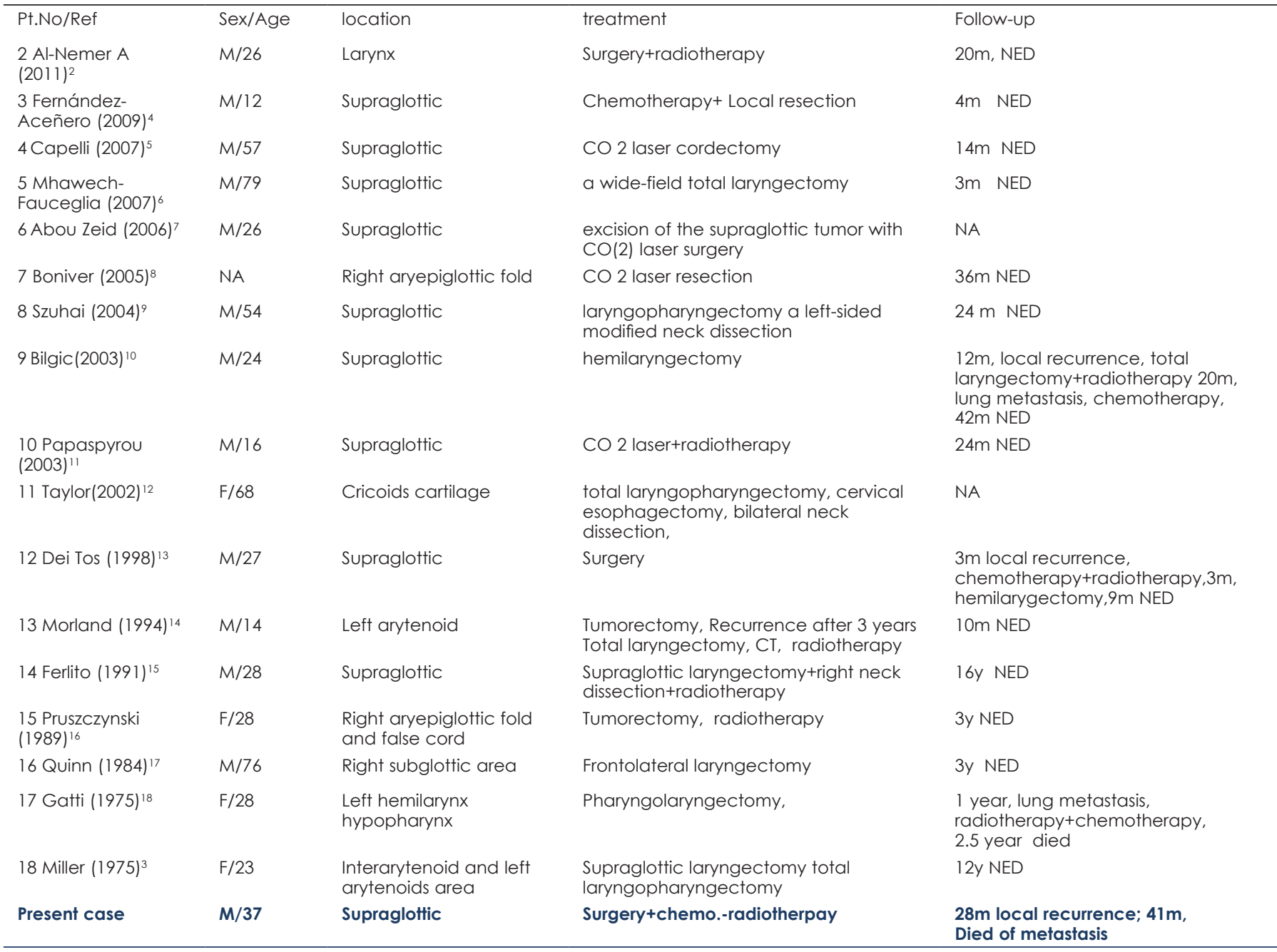

Ref $=$ number of reference; NED = no evidence of disease; NA = not available

(200 mg) at 1-week intervals. CT demonstrated no regression of the metastatic cervical lymph node and lung lesions. In February 2011, the patient underwent additional chemotherapy comprising docetaxel (110 mg, day 1), cisplatin (40 mg, days 1-3), and rh-endostatin (Endostar) (15 mg, days 1-14) every 21 days for up to five cycles. The lesions were not controlled. In July 2011, the chemotherapy was changed to cetuximab (600 mg, day 1) every week for up to three cycles. CT of the lungs and MRI of the head and neck showed that the lesions were larger. On 22 September 2011, PET/CT revealed a $7.5 \times 9 \mathrm{~cm}$ mass in the right submaxillary region with high FDG uptake $\left(\mathrm{SUV}_{\max }=5.2\right)$ involving the right parotid gland, right tongue base, right mandible, jugular vein, carotid artery, and surround- ing muscles, and multiple nodules in the bilateral lungs (largest $=6.68 \mathrm{~cm}$ in diameter; $\mathrm{SUV}_{\max }=6.02$; Figure 5). The cervical mass was treated by local cryoablation, but did not regress. In 11 November 2011, the patient died of brain metastases.

\section{Discussion}

Only 3-9\% of all cases of synovial sarcoma occur in the head and neck. The least frequent site of occurrence is the larynx. To our knowledge, only 18 cases have been reported (including the current case) (Table 1). ${ }^{2-18}$ The reported cases included 13 males, three females, and one case in which the patient's sex was not reported..$^{2-18}$ The male to female 

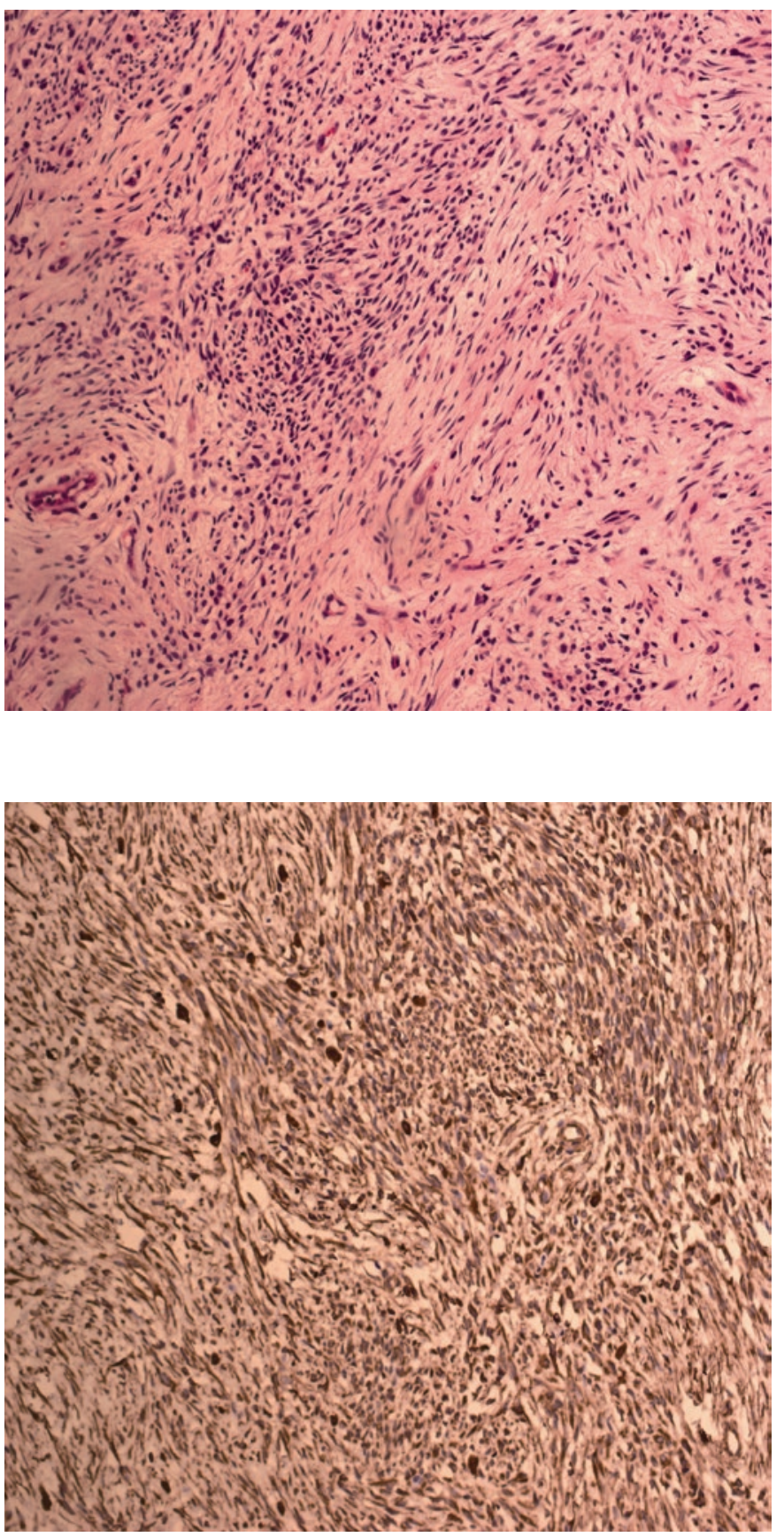

(B)

FIGURE 2. (a) Pathology showed that the tumour consisted of small, uniform spindle cells invading the surrounding muscles (HE×20). (b) Immunohistochemical examination for vimentin was positive (EliVision×20).

ratio was about $4: 1$. The age of the patients ranged from 12 to 79 years at initial presentation, with a mean age of 37 years (data were not available for four patients). ${ }^{2-18}$ Of the 17 patients for whom data were available $2-7,9-18,16(94.1 \%)$ had tumour located in the supraglottic and $1(5.9 \%)$ had tumour in the subglottis; no patient had tumour in the glottis area. For the 16 patients for whom follow-up data were available, the follow-up times ranged from 3 months to 16 years. ${ }^{2-6,8-11,13-18}$ Of these 16 patients, only four (including our patient) developed recurrence and three developed distant metastases. Only two patients (including our patient) died of the disease. The poor outcome might be related to the large extent of the laryngeal synovial sarcoma. ${ }^{18}$

In the majority of cases, the surgical excision with a wide margin is the first treatment choice for synovial carcinoma. The effect of chemotherapy or radiotherapy is controversial. ${ }^{25-27}$ The main treatment regimen for laryngeal synovial sarcoma is surgery, including laryngopharyngectomy, hemilaryngectomy, tumourectomy, total laryngectomy, or tumour resection using a $\mathrm{CO}_{2}$ laser (for localised lesions). ${ }^{3-18}$ Among the patients who underwent $\mathrm{CO}_{2}$ laser surgery, no recurrence or metastasis occurred, and the disease-free survival times were 2 years ${ }^{11}, 3$ years ${ }^{8}$, and 15 months. ${ }^{5}$ The favourable results in this group might be associated with the low volume of the tumours subjected to $\mathrm{CO}_{2}$ laser surgery. $., 8,11$ In cases of laryngeal synovial sarcoma (excluding our case and one case reported by Gatti et al. ${ }^{18}$ ), postoperative chemo/radiotherapy seemed to be effective. ${ }^{2,4,11,14-16}$ No recurrences or metastases occurred, and the longest survival time was 16 years..$^{15}$ Chemo/radiotherapy also seemed to be useful in the treatment of distant metastases and local recurrence. ${ }^{10,14}$ Some reports had a very short follow-up period ( $<2$ years), and the exact outcomes require a further investigation. ${ }^{2,4-6,9,11,13}$ Although our case involved multiple therapeutic strategies, including surgery, radiotherapy, repeated chemotherapies, and targeted therapies, the outcome was poor. This result was similar to that reported by Gatti et al. ${ }^{18}$ Consequently, the ideal treatment has yet to be established because of the limited number of available reports on laryngeal synovial sarcoma.

Magnetic resonance imaging is often recommended as a follow-up modality. ${ }^{21,27}$ Recent studies have indicated that PET is useful in the follow-up of synovial sarcoma. ${ }^{1,23}$ PET/CT has also been used as a diagnostic tool for synovial sarcoma, as well as lymphoma. ${ }^{20,28,29}$ Charest et al. demonstrated $80.0 \%$ sensitivity of PET/CT in 20 soft-tissue synovial sarcomas with a mean $\mathrm{SUV}_{\text {max }}$ of 10.9. ${ }^{28}$ Erturhan et al. reported the use of PET/CT for diagnosis and follow-up in a case of kidney synovial sarcoma. They found slight FDG uptake in the synovial sarcoma and in multiple lymph nodes $\left(\mathrm{SUV}_{\max }=3.5\right)$. PET/ $\mathrm{CT}$ detected no differentiation in multiple lymph nodes in the fourth postoperative month; howev- 


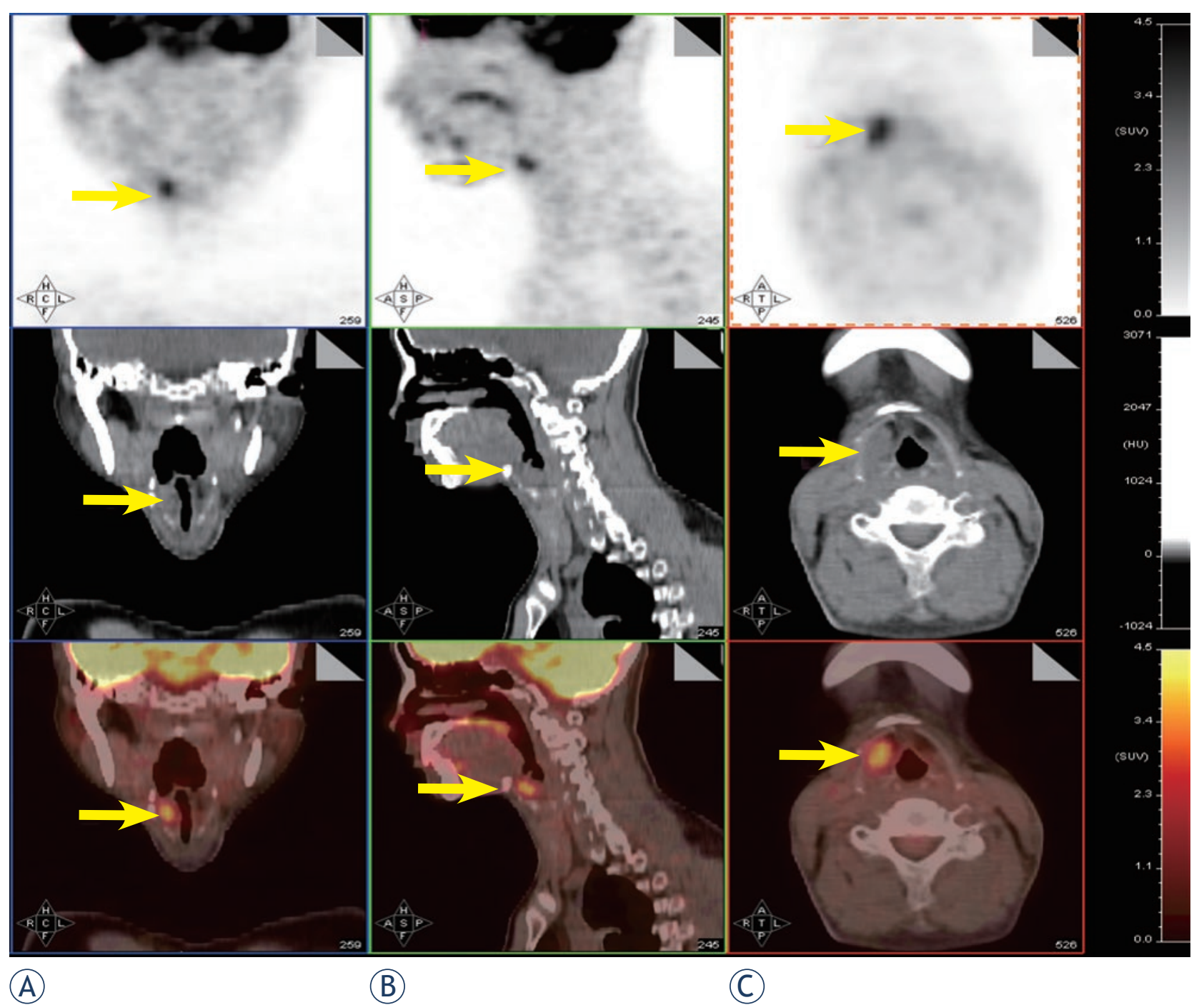

FIGURE 3. PET/CT showed high FDG uptake in the region of the right hypopharynx and laryngeal inlet $\left(S_{U} V_{\max }=4.1\right)$ and no distant metastasis.

er, CT did not show these lymph nodes, and they were reported as normal. ${ }^{23}$ Lisle et al. assessed 44 patients with synovial sarcoma before therapy and resection by FDG-PET. They found that the pretreatment tumour SUV ${ }_{\text {max }}$ predicted the overall and progression-free survival. Patients with $\mathrm{SUV}_{\max }$ $>4.35$ had reduced disease-free survival and were therefore at high risk for local recurrence and metastatic disease. ${ }^{1}$ In our case, although the patient did not undergo pre-treatment PET/CT, three repeated post-treatment PET/CT examinations demonstrated the unsatisfactory treatment outcomes. In this case, $\mathrm{SUV}_{\max }$ did not decrease in response to the various treatments. These findings were consistent with the results of Lisle et al. ${ }^{1}$ Therefore, PET/CT can be a useful workup tool for synovial sarcoma.

\section{Conclusions}

Here, we report a case of laryngeal synovial sarcoma. Although the patient received a comprehensive therapy including surgery, radiotherapy, repeated chemotherapies, and targeted therapies, he had an unfavourable outcome and died of wholebody metastases. Since cases involving the larynx are extremely rare, the treatment of laryngeal synovial sarcoma should follow the guidelines for other tumour sites. To our knowledge, this is the first report of PET/CT findings of laryngeal synovial sarcoma. PET/CT can detect local recurrence and metastasis of laryngeal synovial carcinoma. PET/ $\mathrm{CT}$ can also predict the treatment effect in patients with synovial sarcoma. 

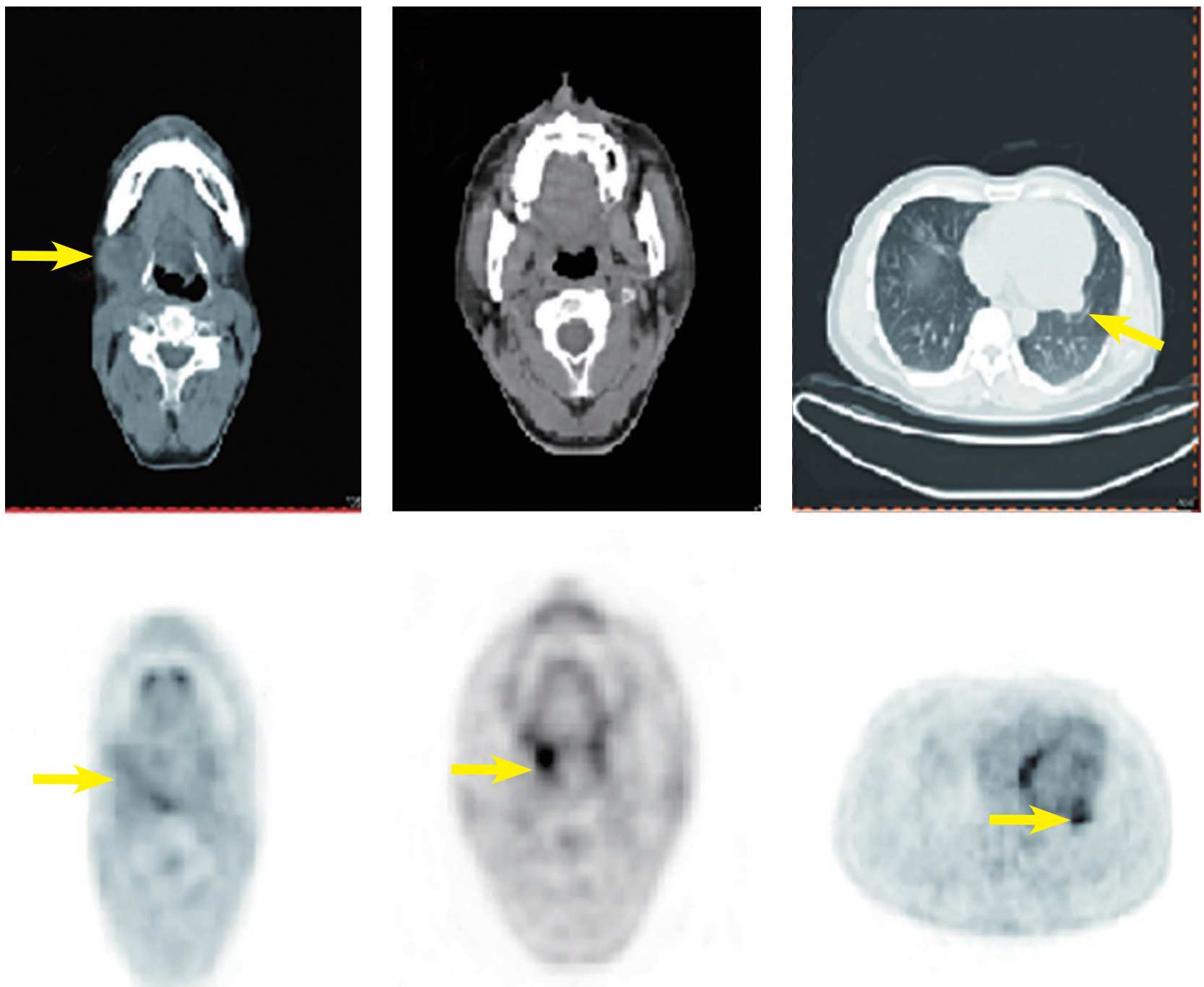

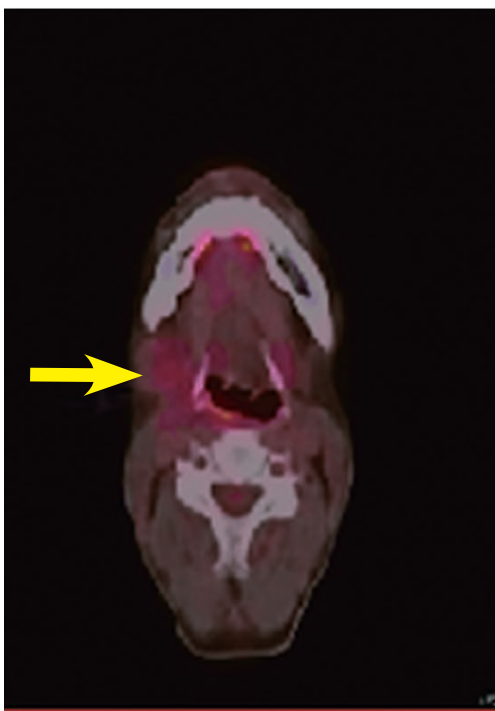

(A)

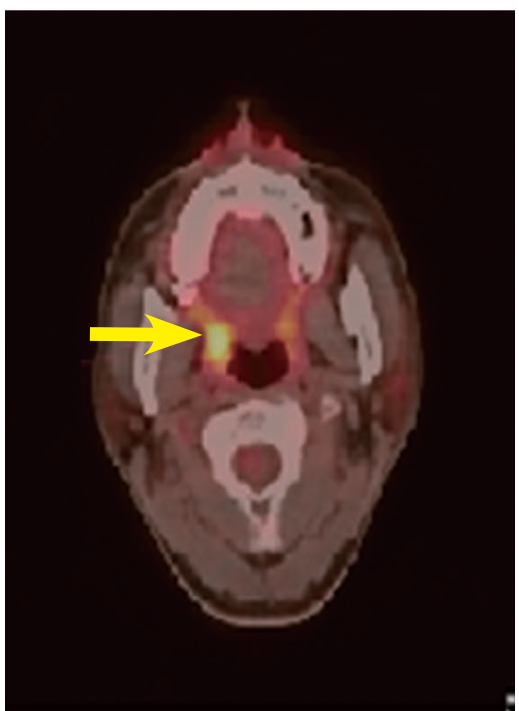

(B)
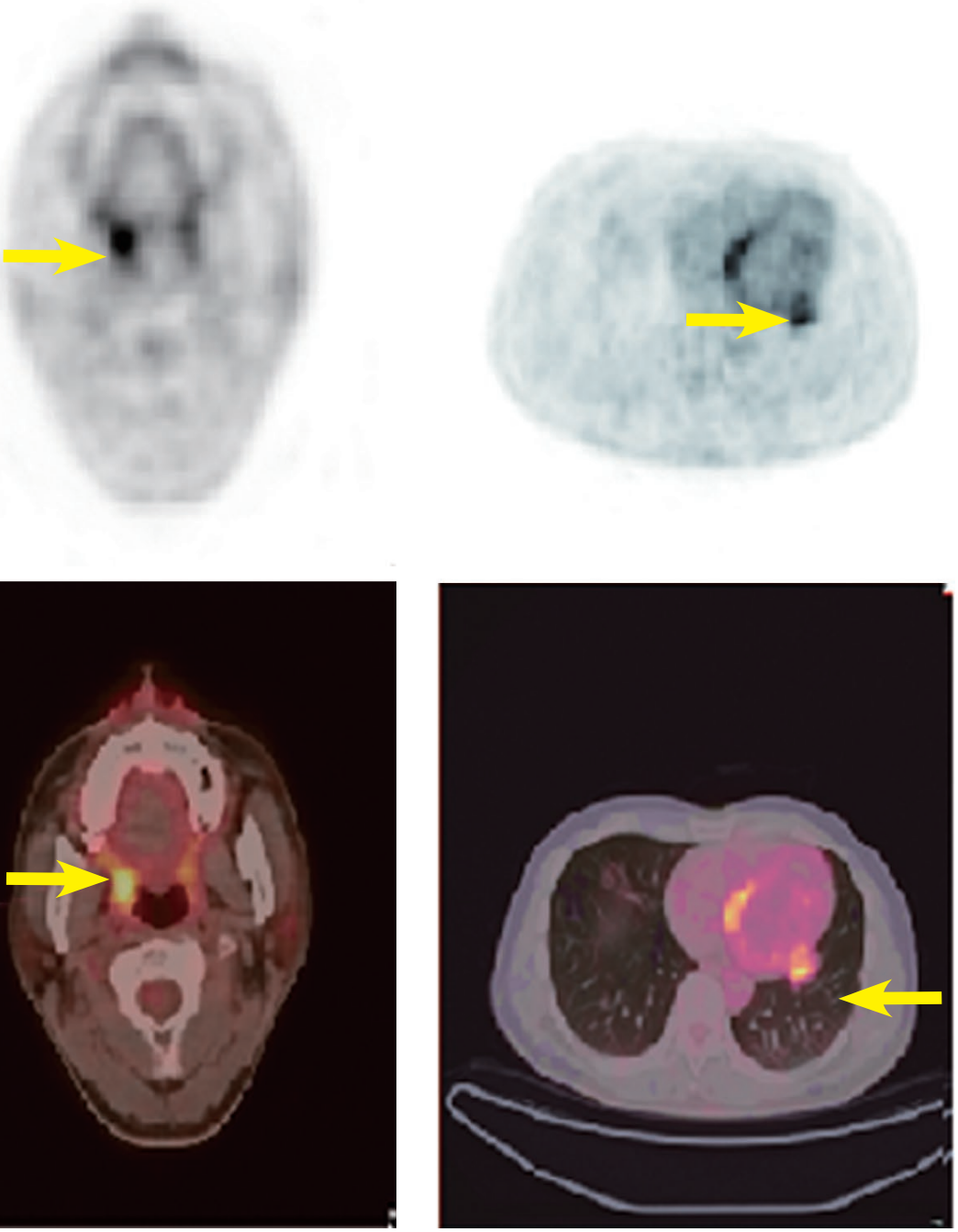

(C)

FIGURE 4. (a, b) Nine months after the second surgery, PET/CT revealed high FDG uptake in the right submaxillary lymph node (SUV $\left.{ }_{\text {max }}=3.2\right)$, right oropharynx $\left(S U V_{\text {max }}=5.4\right)$ and $(c)$ multiple nodules in both lungs $\left(S U V_{\text {max }}=4.6\right)$. 


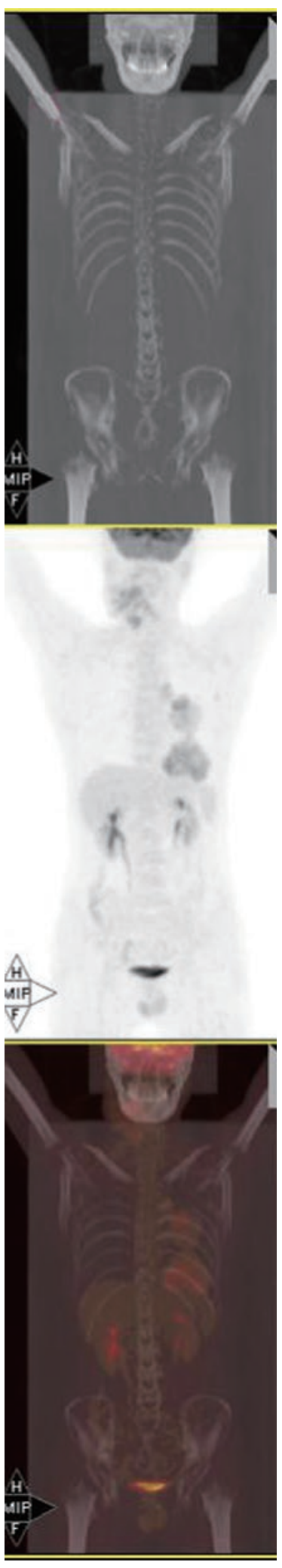

(A)
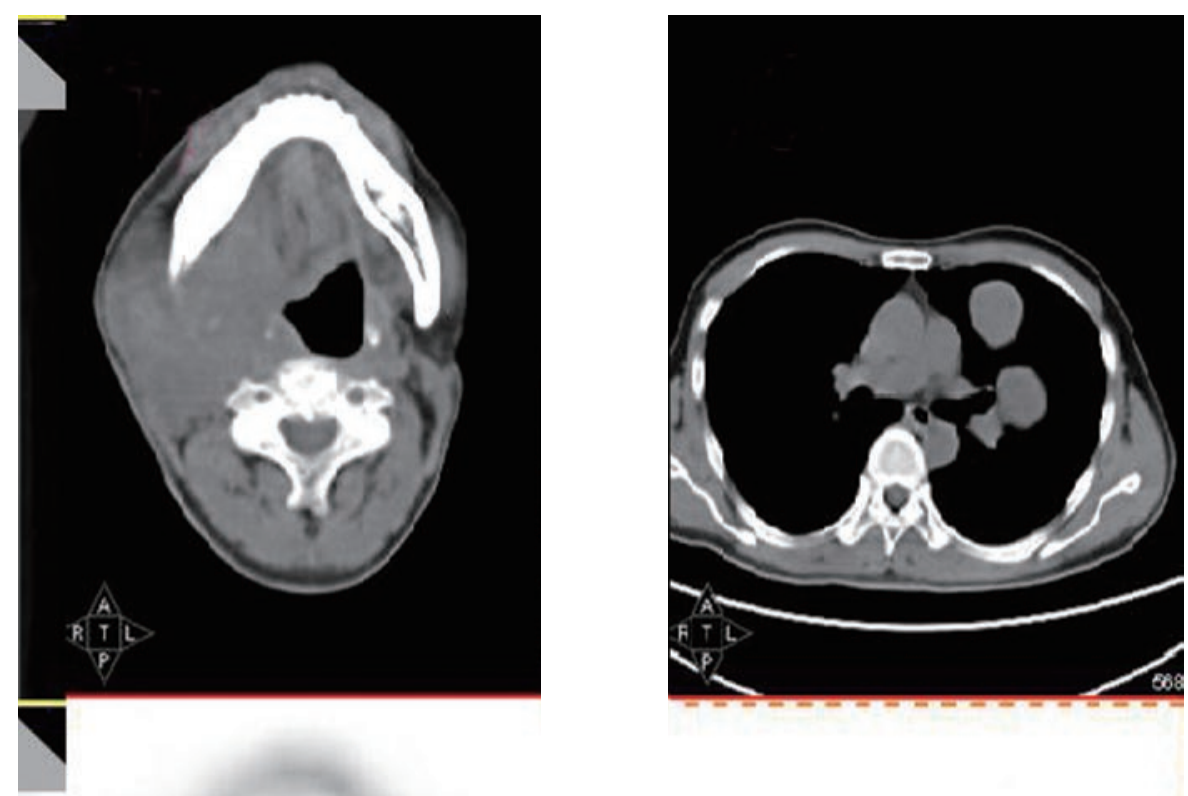

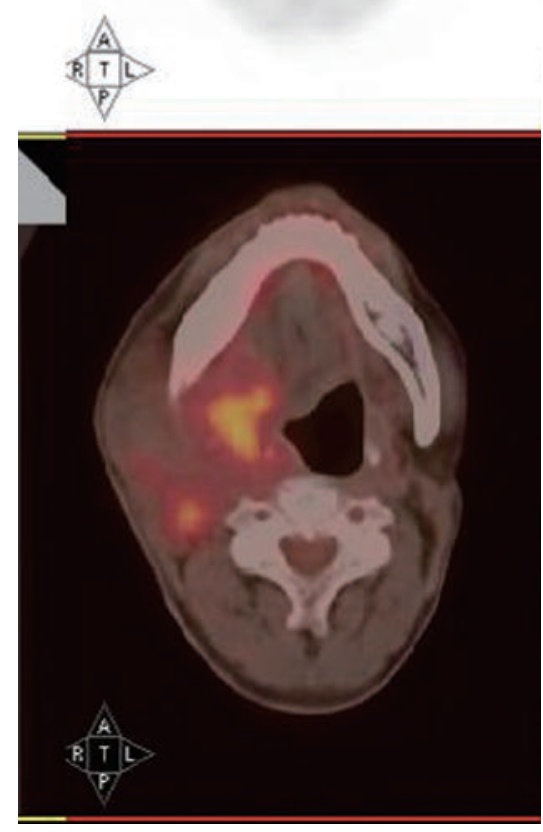

(B)
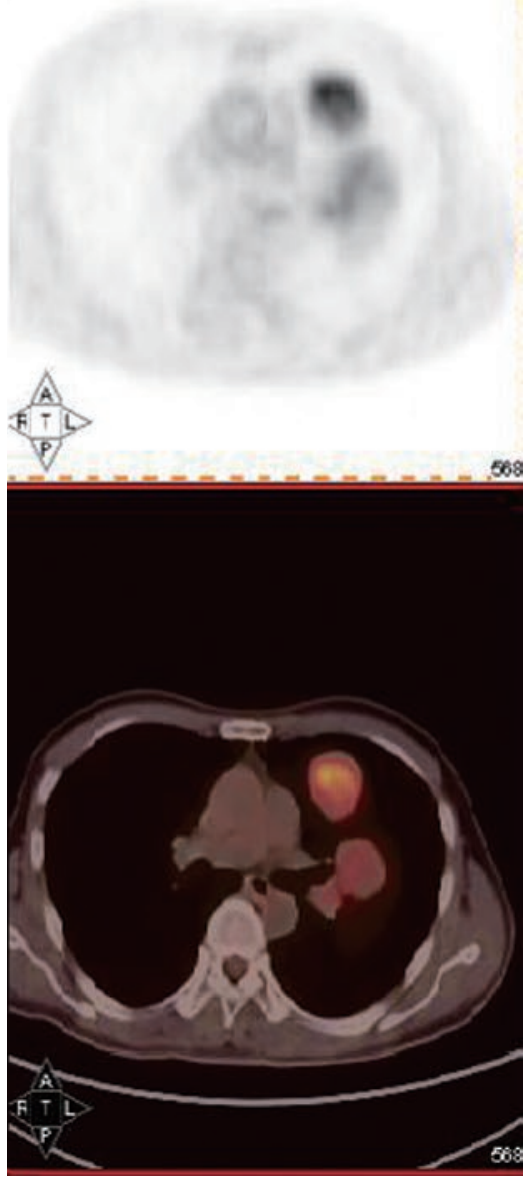

(C)

FIGURE 5. After radiotherapy, repeated chemotherapies and targeted therapies, (a) a whole body scan showed FDG uptake in the right neck and lung. (b) PET/CT revealed a $7.5 \times 9-\mathrm{cm}$ mass in the right submaxillary region with high FDG uptake (SUV ${ }_{\text {max }}=5.2$ ) involving the right parotid gland, right tongue base, right mandible, jugular vein, carotid artery, and surrounding muscles. (c) Multiple nodules in both lungs, were evident with the largest being up to $6.68 \mathrm{~cm}$ in diameter $\left(S U V_{\max }=6.02\right)$. 


\section{References}

1. Lisle JW, Eary JF, O'Sullivan J, Conrad EU. Risk assessment based on FDGPET imaging in patients with synovial sarcoma. Clin Orthop Relat Res 2009; 467: 1605-11.

2. Al-Nemer A, El-Shawarby MA. Laryngeal synovial sarcoma: Case report and literature review. Gulf J Oncolog 2011; 1: 52-6.

3. Miller LH, Santaella-Latimer L, Miller T. Synovial sarcoma of the larynx. Trans Sect Otolaryngol Am Acad Ophthalmol Otolaryngol 1975; 80: 448-451.

4. Fernández-Aceñero MJ, Larach F, Ortega-Fernández C. Non-epithelial lesions of the larynx: review of the 10-year experience in a tertiary Spanish hospital. Acta Otolaryngol 2009; 129: 108-12.

5. Capelli M, Bertino G, Morbini P, Proh M, Falco CE, Benazzo M. CO2 laser in the treatment of laryngeal synovial sarcoma: a clinical case. Tumori 2007; 93: $296-9$

6. Mhawech-Fauceglia P, Ramzy P, Bshara W, Sait S, Rigual N. Synovial sarcoma of the larynx in a 79-year-old woman, confirmed by karyotyping and fluorescence in situ hybridization analysis. Ann Diagn Pathol 2007; 11: 223-7.

7. Abou Zeid HA, Arab SA, Al-Ghamdi AM, Al-Qurain AA, Mokhazy KM. Airway management of a rare huge-size supraglottic mass. Saudi Med J 2006; 27: 711-3.

8. Boniver V, Moreau P, Lefebvre P. Synovial sarcoma of the larynx: case report and literature review. B-ENT 2005; 1: 47-51.

9. Szuhai $\mathrm{K}$, Knijnenburg J, ljszenga $\mathrm{M}$, Tanke $\mathrm{HJ}$, Baatenburg de Jong RJ, Bas Douwes Dekker P, et al. Multicolor fluorescence in situ hybridization analysis of a synovial sarcoma of the larynx with a $\mathrm{t}(\mathrm{X} ; 18)(\mathrm{p} 11.2 ; \mathrm{q} 11.2)$ and trisomies 2 and 8. Cancer Genet Cytogenet 2004; 153: 48-52.

10. Bilgic B, Mete O, Oztürk SA, Demiryont M, Keles N, Basaran M. Synovial sarcoma: a rare tumor of larynx. Pathol Oncol Res 2003; 9: 242-5.

11. Papaspyrou S, Kyriakides G, Tapis M. Endoscopic CO2 laser surgery for large synovial sarcoma of the larynx. Otolaryngol Head Neck Surg 2003; 129: 630-1.

12. Taylor SM, Ha D, Elluru R, El-Mofty S, Haughey B, Wallace M. Synovial sarcoma of the pericricoidal soft tissue. Otolaryngol Head Neck Surg 2002; 126: 428-9.

13. Dei Tos AP, Dal Cin P, Sciot R, Furlanetto A, Da Mosto MC, Giannini C, et al. Synovial sarcoma of the larynx and hypopharynx. Ann Otol Rhinol Laryngol 1998; 107: 1080-5

14. Morland B, Cox G, Randall C, Ramsay A, Radford M. Synovial sarcoma of the larynx in a child: case report and histological appearances. Med Pediatr Oncol 1994; 23: 64-8.

15. Ferlito A, Caruso G. Endolaryngeal synovial sarcoma. An update on diagnosis and treatment. J Otorhinolaryngol Relat Spec 1991; 53: 116-9.

16. Pruszczynski M, Manni JJ, Smedts F. Endolaryngeal synovial sarcoma: case report with immunohistochemical studies. Head Neck 1989; 11: 76-80.

17. Quinn HJ Jr. Synovial sarcoma of the larynx treated by partial laryngectomy Laryngoscope 1984; 94: 1158-61.

18. Gatti WM, Strom CG, Orfei E. Synovial sarcoma of the laryngopharynx. Arch Otolaryngol 1975; 101: 633-6.

19. Ishiki H, Miyajima C, Nakao K, Asakage T, Sugasawa M, Motoi T. Synovia sarcoma of the head and neck: rare case of cervical metastasis. Head Neck 2009; 31: 131-5

20. Polverosi R, Muzzio PC, Panunzio A, Pasquotti G, Schiavon M, Rea F. Synovial sarcoma: CT imaging of a rare primary malignant tumour of the thorax. Radiol Med 2011; 116: 868-75.

21. Rangheard AS, Vanel D, Viala J, Schwaab G, Casiraghi O, Sigal R. Synovial sarcomas of the head and neck: CT and MR imaging findings of eight patients. Am J Neuroradiol 2001; 22: 851-57.

22. Ricard F, Cimarelli S, Deshayes E, Mognetti T, Thiesse P, Giammarile F. Additional Benefit of F-18 FDG PET/CT in the staging and follow-up of pediatric rhabdomyosarcoma. Clin Nucl Med 2011; 36: 672-7.

23. Erturhan S, Seçkiner I, Zincirkeser S, Erbagci A, Celik M, Yagci F, et al. Primary synovial sarcoma of the kidney: use of PET/CT in diagnosis and follow-up. Ann Nucl Med 2008; 22: 225-9.
24. Skytting B. Synovial sarcoma. A Scandinavian sarcoma group profect. Acta Orthop Scand 2000; Suppl. 291: 1-28.

25. Lee N, Shin E. Treatment outcomes for patients with synovial sarcoma of the head and neck. Expert Rev Anticancer Ther 2008; 8: 371-3.

26. Janevska V, Filipovski V, Banev S, Janevski V, Jovcevski A, Spasevska L, et al. Synovial Sarcoma of the liver - a case report. Maced J Med Sc 2011; 4: 185-91.

27. Kusuma S, Skarupa DJ, Ely KA, Cmelak AJ, Burkey BB. Synovial sarcoma of the head and neck: a review of its diagnosis and management and a report of a rare case of orbital involvement. Ear Nose Throat 2010; 89: 280-3.

28. Charest M, Hickeson M, Lisbona R, Novales-Diaz JA, Derbekyan V, Turcotte RE. FDG PET/CT imaging in primary osseous and soft tissue sarcomas: a retrospective review of 212 cases. Eur J Nucl Med Mol Imaging 2009; 36: 1944-51.

29. Huić $D$, Mutvar A, Kinda-Bašić S, Aurer I, Ciglar M, Grošev D, et al. Negative predictive value of F-18-FDG coincidence PET in patients with Hodgkin's disease and a residual mass after therapy: a retrospective diagnostic test study. Radiol Oncol 2009; 43: 258-63. 